Article

\title{
Characterization and Expression Profiling of Camellia sinensis Cinnamate 4-hydroxylase Genes in Phenylpropanoid Pathways
}

\author{
Jinxin Xia ${ }^{1,2,+}$, Yajun Liu ${ }^{1,2,+}$, Shengbo Yao ${ }^{2}$, Ming Li ${ }^{1,2}$, Mengqing Zhu ${ }^{1,2}$, Keyi Huang ${ }^{1,2}$, \\ Liping Gao ${ }^{1,2, *}$ and Tao Xia ${ }^{2, *}$ \\ 1 School of Life Science, Anhui Agricultural University, Hefei 230036, Anhui, China; \\ JinxinXia@ahau.edu.cn (J.X.); liuyajun1228@163.com (Y.L.); liming4802@163.com (M.L.); \\ mengqing1234567@163.com (M.Z.); huluobuhashiqi@163.com (K.H.) \\ 2 State Key Laboratory of Tea Plant Biology and Utilization, Anhui Agricultural University, \\ 130 West Changjiang Rd, Hefei 230036, Anhui, China; yaoandtea@163.com \\ * Correspondence: gaolp62@126.com (L.G.); xiatao62@126.com (T.X.); Tel.: +86-551-5786-129 (L.G.); \\ +86-551-5786-003 (T.X.); Fax: +86-551-5785-729 (L.G. \& T.X.) \\ + These authors contributed equally to this work.
}

Received: 27 June 2017; Accepted: 25 July 2017; Published: 1 August 2017

\begin{abstract}
Cinnamate 4-hydroxylase $(\mathrm{C} 4 \mathrm{H})$, a cytochrome P450-dependent monooxygenase, participates in the synthesis of numerous polyphenoid compounds, such as flavonoids and lignins. However, the $\mathrm{C} 4 \mathrm{H}$ gene number and function in tea plants are not clear. We screened all available transcriptome and genome databases of tea plants and three $\mathrm{C} 4 \mathrm{H}$ genes were identified and named $\mathrm{CsC}_{4} \mathrm{Ha}, \mathrm{CsC} 4 \mathrm{Hb}$, and $\mathrm{CsC}_{s} 4 \mathrm{Hc}$, respectively. Both $\mathrm{CsC}_{s} 4 \mathrm{Ha}$ and $\mathrm{Cs}_{5} \mathrm{CH} b$ have 1518-bp open reading frames that encode 505-amino acid proteins. $\mathrm{CsC}_{5} \mathrm{Hc}$ has a 1635 -bp open reading frame that encodes a 544-amino acid protein. Enzymatic analysis of recombinant proteins expressed in yeast showed that the three enzymes catalyzed the formation of $p$-coumaric acid (4-hydroxy trans-cinnamic acid) from trans-cinnamic acid. Quantitative real-time PCR (qRT-PCR) analysis showed that CsC4Ha was highly expressed in the 4th leaf, $\mathrm{CsC} 4 \mathrm{Hb}$ was highly expressed in tender leaves, while $\mathrm{CsC} 4 \mathrm{Hc}$ was highly expressed in the young stems. The three $\mathrm{Cs} C 4 \mathrm{Hs}$ were induced with varying degrees by abiotic stress treatments. These results suggest they may have different subcellular localization and different physiological functions.
\end{abstract}

Keywords: Camellia sinensis; phenylpropanoid; cinnamate 4-hydroxylase; expression pattern; abiotic stress

\section{Introduction}

Tea, one of the most popular non-alcoholic beverages in the world, is rich in polyphenoid compounds derived from phenylpropanoid pathways, e.g., catechins (flavan-3-ols), flavonols, and their derivatives [1]. These compounds are closely related to the flavor of tea [2] and benefit human health through their anti-retroviral, anti-hypertensive, anti-inflammatory, anti-aging, and insulin-sensitizing activities. In addition, these compounds inhibit low-density lipoprotein (LDL) oxidation and reduce the risk of a wide range of chronic diseases, including cardiovascular disease, cancer, and osteoporosis [3].

The core reactions in phenylpropanoid biosynthesis that produce important secondary metabolites participating in plant development and defense responses [4] involve three enzymes, phenylalanine ammonia-lyase (PAL; EC 4.3.1.5), cinnamate 4-hydroxylase (C4H, EC 1.14.13.11), and 4-coumarate: coenzyme A ligase (4CL; EC 6.2.1.12). C4H, a member of the cytochrome P450 family [5], catalyzes the formation of $p$-coumaric acid (4-hydroxy trans-cinnamic acid) from trans-cinnamic acid. 
As the upstream enzyme, $\mathrm{C} 4 \mathrm{H}$ forms 4-coumarate (or para-coumarate), which is used to yield coenzyme A (CoA)-thioester by 4CL. 4-Coumaroyl-CoA is the precursor for many phenylpropanoid compounds including flavonoids and lignin[6] (Figure 1). Lignin plays an important role in plant defense mechanisms against pathogens $[7,8]$. Flavonoids, which originate from the flavonoid synthetic pathway located downstream of the phenylpropanoid pathway, include flavanols, anthocyanins, proanthocyanidins, flavonols, and flavones. Flavonoids protect plants from different biotic and abiotic stresses, act as unique ultraviolet (UV)-filters, and function as signal molecules, allelopathic compounds, phytoalexins, detoxifying agents, and antimicrobial defense compounds [9].

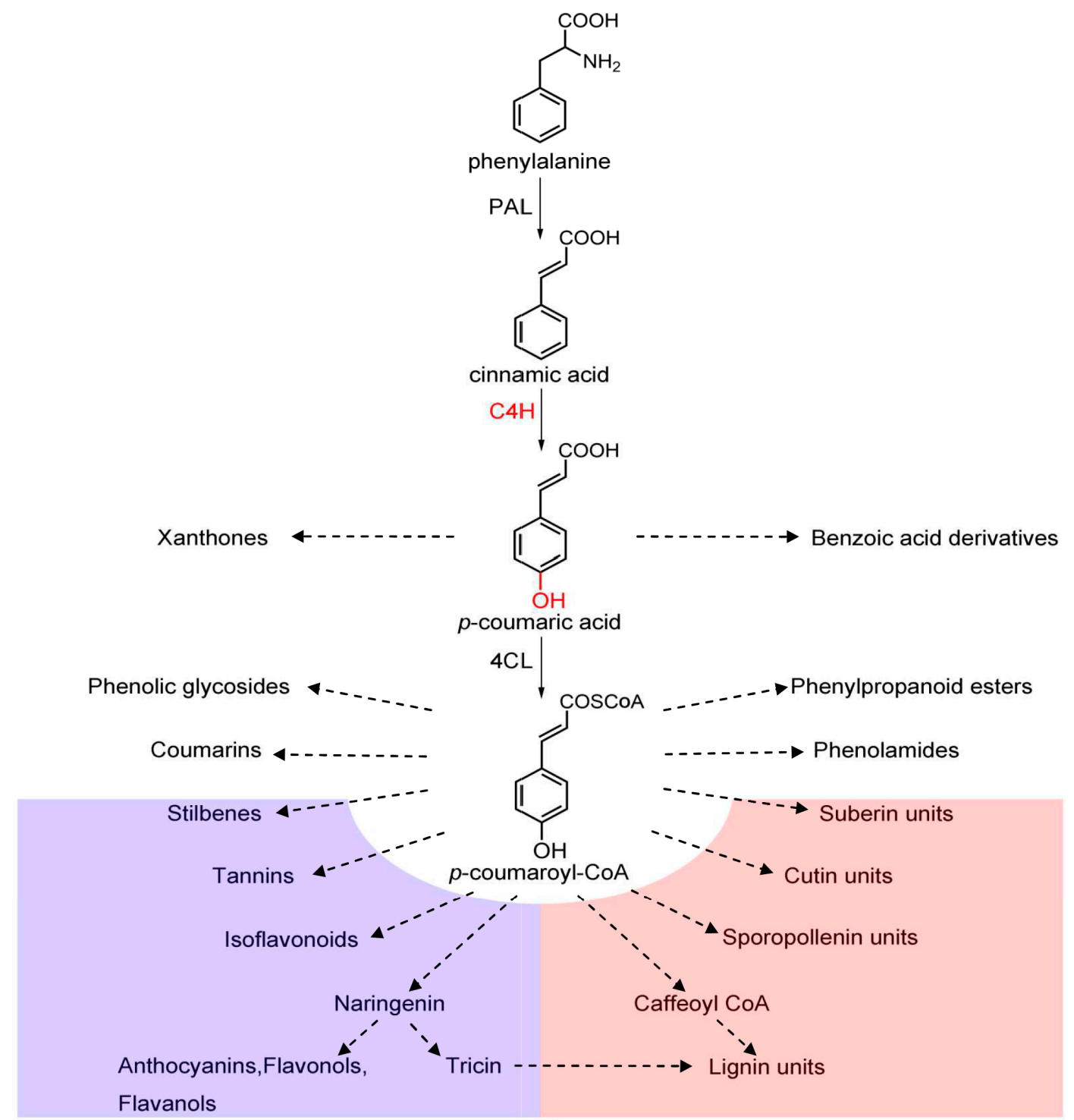

Figure 1. Schematic view of some branches of the phenylpropanoid pathway. PAL: phenylalanine ammonia-lyase; $\mathrm{C} 4 \mathrm{H}$ : cinnamate 4-hydroxylase; 4CL: 4-coumarate: coenzyme A ligase.

$\mathrm{C} 4 \mathrm{H}$, a member of the cytochrome P450 CYP73A group, has been most extensively studied among plant P450s [10-14]. The number of $C 4 H$ gene families varies considerably between different plants. Arabidopsis, Parthenocissus henryana, parsley, Scutellaria baicalensis, and Korean black raspberry are thought to contain only one gene for $\mathrm{C} 4 \mathrm{H}[13,15,16]$. On the contrary, in Leucaena leucocephala, Camptotheca acuminata, and Brassica napus, $\mathrm{C} 4 \mathrm{H}$ is encoded by a small gene family $[5,17,18]$. 
In the currently online available database of transcriptomes and genomes of tea plants, three $\mathrm{CsC} 4 \mathrm{H}$ transcripts have been screened, but their functions in tea plants remain unclear. For example, it remains to be determined whether their coding candidate $\mathrm{Cs} C 4 \mathrm{H}$ enzymes have enzymatic activities or whether these genes participate in the response of tea plants to biotic or abiotic stresses.

In this study, we cloned the three genes, $\mathrm{CsC}_{5} 4 \mathrm{Ha}, \mathrm{Cs} \mathrm{C} 4 \mathrm{Hb}$, and $\mathrm{CsC}_{\mathrm{S}} 4 \mathrm{Hc}$, verified their enzymatic functions using yeast recombinant proteins, and analyzed their expression profiles in tea plants subjected various abiotic stresses.

\section{Materials and Methods}

\subsection{Plant Materials}

Samples of the tea plant Camellia sinensis cv. 'Shucazao' were obtained from the experimental tea garden of Anhui Agricultural University in Hefei, China. Leaves at six different developmental stages (bud, 1st leaf, 2nd leaf, 3rd leaf, 4th leaf, and mature leaf), and young stems and young roots were collected. The samples were immediately frozen in liquid nitrogen and stored at $-80^{\circ} \mathrm{C}$.

With respect to the abiotic stresses, the approximately $10 \mathrm{~cm}$ long shoots were cultured in water for one day and then subjected to the treatments. The samples were treated under $100 \mathrm{mM}$ abscisic acid (ABA) and $90 \mathrm{mM}$ sucrose for $12 \mathrm{~h}, 20 \mathrm{mM}$ salicylic acid (SA) treatment for $48 \mathrm{~h}$, respectively. The control plants were cultivated in deionized water. For heat stress, the shoots were treated at $50{ }^{\circ} \mathrm{C}$ for $30 \mathrm{~min}$ with the controls treated at $20^{\circ} \mathrm{C}$.

The tender shoots were illuminated under ultraviolet radiation $\mathrm{b}$ (UVB) for $30 \mathrm{~min}$, blue light (455-460 nm) for $48 \mathrm{~h}$, red light $(655-660 \mathrm{~nm})$ for $48 \mathrm{~h}$, and in dark for $12 \mathrm{~h}$, respectively. The control plants were treated under white light.

All samples were immediately frozen in liquid nitrogen, and total RNA was extracted as described below.

The yeast strain (Saccharomyces cerevisiae cv. WAT11) was kindly provided by Conagen Inc. (Bedford, MA, USA).

\subsection{RNA and cDNAPreperation}

Total RNA was extracted from the tea plants using RNAiso Mate and RNAiso Plus (Takara, Dalian, China) according to the manufacturer's instructions. The quality of the RNA was checked using gel electrophoresis, and total RNA was quantified using NanoVue plus (GE Healthcare, Waukesha, WI, USA). The different cDNAs were reverse transcribed using a PrimeScript RT Reagent Kit (Takara), following the manufacturer's protocol.

\subsection{Cloning of $\mathrm{CsC} 4 \mathrm{Ha}, \mathrm{CsC} 4 \mathrm{Hb}$, and $\mathrm{CsC} 4 \mathrm{Hc}$}

The databases accessed in the National Center for Biotechnology Information (NCBI) for screening the candidate genes include nine transcriptome databases, such as 'Fudingdabaicha' (TSA: GAAC01000001-GAAC01052919), 'Longjing43' (TSA: GBBZ01000001-GBBZ01049010, HP701085-HP777243), 'Xinyangdaye' (TSA: GEFQ01000001-GEFQ01129526), 'Zhongcha302' (TSA: GBKQ01000001-GBKQ01063798), 'Shuchazao' (from our laboratory), 'Huangkui' (from our laboratory), 'Ziya' (from our laboratory), 'Teenali' (TSA: GBRC01000001-GBRC01033639), 'Hongye2' (TSA: KA279444-KA304315), and a genome database (www.plantkingdomgdb.com/tea_tree/).

The $\mathrm{Cs} C 4 \mathrm{H}$ mRNAs from the transcriptome database were subjected to standard polymerase chain reaction (PCR) reactions, with the primers designed according to the cDNA sequence (synthesized by the Beijing Genomics Institute, Beijing, China; Table 1). The cDNA strands for end-to-end PCR were synthesized using Phusion High-Fidelity DNA Polymerase (Thermo Scientific, Vilnius, Lithuania). PCR products were gel purified using an agarose gel extraction kit (Takara), ligated into a pEASY-Blunt Simple T vector (TransGen Biotech, Beijing, China), and transformed into Escherichia coli 
DH5 $\alpha$ competent cells for sequencing. The results were assembled using DNAMAN V6 software (Lynnon Corporation, San Ramon, CA, USA). Briefly, end-to-end PCR was performed under the following conditions: $98^{\circ} \mathrm{C}$ for $30 \mathrm{~s}, 30$ cycles at $98^{\circ} \mathrm{C}$ for $10 \mathrm{~s}, 56^{\circ} \mathrm{C}$ for $30 \mathrm{~s}, 72^{\circ} \mathrm{C}$ for $90 \mathrm{~s}$, and a final extension at $72{ }^{\circ} \mathrm{C}$ for $10 \mathrm{~min}$.

Table 1. Primers used in the study.

\begin{tabular}{|c|c|c|c|}
\hline Gene & Primer & Primer Sequence & Use \\
\hline \multirow{4}{*}{$\mathrm{CsC} 4 \mathrm{Ha}$} & $\mathrm{CsC} 4 \mathrm{Ha}-\mathrm{F}$ & 5'-ATGGATCTTCTCСТCCTAGAGAAG-3' & Cloning \\
\hline & $\mathrm{CsC} 4 \mathrm{Ha}-\mathrm{R}$ & $5^{\prime}$-TCAGAACGATCTTGGTTTCAGAAC-3' & Cloning \\
\hline & qPCR-F & 5'-GCTCTCTGGCTATGACATCCCT-3' & qRT-PCR \\
\hline & qPCR-R & 5'-TCCTCCTTCCGACACCAAACG-3' & qRT-PCR \\
\hline \multirow{4}{*}{$\mathrm{CsC} 4 \mathrm{Hb}$} & $\mathrm{CsC} 4 \mathrm{Hb}-\mathrm{F}$ & 5'-ATGGATCTTCTTCTCCTAGAG-3' & Cloning \\
\hline & $\mathrm{CsC} 4 \mathrm{Hb}-\mathrm{R}$ & $5^{\prime}$-TTAAAATGATCTTGGTTTCATC-3' & Cloning \\
\hline & gPCR-F & $5^{\prime}$-GCTCGGCAGCTATGACATCC-3' & qRT-PCR \\
\hline & qPCR-R & $5^{\prime}$-СТССТССТАССАACACCGAATG-3' & qRT-PCR \\
\hline \multirow{4}{*}{$\mathrm{CsC} 4 \mathrm{Hc}$} & $\mathrm{CsC} 4 \mathrm{Hc}-\mathrm{F}$ & 5'-ATGGGCAAACTTATTACAAAATTTAT-3' & Cloning \\
\hline & $\mathrm{CsC} 4 \mathrm{Hc}-\mathrm{R}$ & 5'-TTAAACTTTTTTTGAACGAACAATTG-3' & Cloning \\
\hline & qPCR-F & 5'-GCGATGAAATCTCAACCGTCC-3' & qRT-PCR \\
\hline & qPCR-R & $5^{\prime}$-TGACCACAACCTTTGACTCCTTAG-3' & qRT-PCR \\
\hline
\end{tabular}

\subsection{Quantitative Real-Time PCR}

All primers were blasted against the NCBI database (United States National Library of Medicine, Bethesda, MD, USA) to guarantee specificity. The values were normalized against the expression levels of the housekeeping gene glyceraldehyde-3-phosphate dehydrogenase (GAPDH) from the tea plant [19]. The first-strand cDNA samples for quantitative real-time PCR (qRT-PCR) were synthesized using the PrimeScript RT reagent Kit (Takara). The PCR mixture contained cDNA template (approximately $0.01 \mu \mathrm{g} / \mu \mathrm{L}$ ), $10 \mu \mathrm{L}$ SYBR Green PCR Master Mix (Takara), and $200 \mathrm{nmol} / \mathrm{L}$ of each gene-specific primer in a final volume of $20 \mu \mathrm{L}$.

Real-time PCR was performed as suggested by Lei Zhao et al. [20]. Data were expressed as the mean value of three biological replicates, normalized against the expression levels of GAPDH. The relative expression was derived using the $2^{-\Delta \Delta C T}$ method. $\triangle \mathrm{CT}=\mathrm{CT}_{\text {target }}-\mathrm{CT}_{\text {internal standard }}$, $-\Delta \Delta \mathrm{CT}=-\left(\Delta \mathrm{CT}_{\text {target }}-\Delta \mathrm{CT}\right.$ control $)$, where $\mathrm{CT}_{\text {target }}$ and $\mathrm{CT}_{\text {internal standard }}$ are the cycle threshold $(\mathrm{CT})$ values for the target and housekeeping genes, respectively.

\subsection{Heterologous Expression and Enzymatic Activity Analysis of Recombinant CsC4Hs}

The PCR products of $\mathrm{CsC}_{s} 4 \mathrm{Ha}, \mathrm{CsC}_{s} 4 \mathrm{Hb}$, and $\mathrm{Cs}_{s} \mathrm{H} H c$, obtained using end-to-end PCR, were gel purified and ligated into $\mathrm{pENTR/TEV/D-TOPO} \mathrm{vectors} \mathrm{using} \mathrm{Top} \mathrm{cloning} \mathrm{(pENTR} \mathrm{/D-TOPO} \mathrm{Cloning}$ Kits, Invitrogen, Carlsbad, CA, USA). Then, the entry vectors pENTR-CsC4Ha, pENTR-CsC4H,b and pENTR-CsC4Hc were cloned into the destination vector pYES-DEST52 using the Gateway LR Clonase enzyme (Invitrogen, Carlsbad, CA, USA). The resulting pYES-DEST52-CsC4Ha, pYES-DEST52-CsC4Hb, and pYES-DEST52-CsC4Hc were transformed into S. cerevisiae WAT11 using Frozen-EZ yeast Transformation II (Zymo Research, Irvine, CA, USA). Yeast cells were propagated at $28{ }^{\circ} \mathrm{C}$ for $12 \mathrm{~h}$ in 10-mL Synthetic Dropout-Ura Media (SD-U) liquid medium containing $20 \mathrm{~g} / \mathrm{L}$ glucose, by inoculation of a single colony from an SD-U plate. The thalli collected were transferred into $10-\mathrm{mL}$ SD-U medium containing $20 \mathrm{~g} / \mathrm{L}$ galactose and were grown at $28^{\circ} \mathrm{C}$ for $5 \mathrm{~h}$. The substrate $t$-cinnamate was added to the yeast culture to a final concentration of $0.2 \mathrm{mM}$ and incubated at $28^{\circ} \mathrm{C}$ for $1 \mathrm{~h}$. The reactions were terminated by sonication for $15 \mathrm{~min}$ and the addition of methanol. Microzymes from each reaction were extracted using the same volume of methanol after high-speed 
centrifugation $(1300 \mathrm{rpm}, 160 \times g, 10 \mathrm{~min})$ and $0.22-\mu \mathrm{m}$ membrane filtration for high-performance liquid chromatogram (HPLC) analysis at 275 and $309 \mathrm{~nm}$.

HPLC: After removal of the denatured proteins by centrifugation, the formation of $p$-coumaric acid was analyzed using a HPLC equipped with an Altima C18 analytical column $(250 \mathrm{~mm} \times 4.6 \mathrm{~mm}$, $5 \mu \mathrm{m})$ (Agilent, Santa Clara, CA, USA) with a gradient elution of solvent $\mathrm{B}\left(\mathrm{CH}_{3} \mathrm{CN}\right)$ and solvent $\mathrm{A}(1 \%$ acetic acid) at a flow rate of $1 \mathrm{~mL} / \mathrm{min}$ at $35^{\circ} \mathrm{C}$ over a 30-min period as follows: $0 \mathrm{~min}, 10 \%$ solvent $\mathrm{B}$; $5 \mathrm{~min}, 15 \%$ solvent $\mathrm{B} ; 15 \mathrm{~min}, 40 \%$ solvent $\mathrm{B} ; 20 \mathrm{~min}, 60 \%$ solvent $\mathrm{B} ; 25 \mathrm{~min}, 80 \%$ solvent $\mathrm{B}$, and $30 \mathrm{~min}$, $10 \%$ solvent $\mathrm{B}$. A diode array detector (DAD) was used for monitoring purposes. All experiments were performed in duplicate.

\subsection{Bioinformatics Analysis}

Cinnamate 4-hydroxylase candidate genes were analyzed using online bioinformatics tools from NCBI and ExPASy (SIB Swiss Institute of Bioinformatics, Lausanne, Switzerland). Open reading frame (ORF) identification was performed using an online program (National Center for Biotechnology Information, U.S. National Library of Medicine, Bethesda, MD, USA) [21]. The amino acid sequence of the ORF was deduced and analyzed using the ProtParam tool (National Center for Biotechnology Information, U.S. National Library of Medicine) [22]. CsC4Hs and other known C4H sequences retrieved from NCBI database (U.S. National Library of Medicine) were aligned with DNAMAN (Lynnon Corporation, San Ramon, CA, USA) [20]. Subsequently, a phylogenetic tree was constructed using the neighbor-joining (NJ) method with MEGA 5.0 software (Mega, Raynham, MA, USA). The reliability of the tree was measured using bootstrap analysis based on 1000 replicates.

\section{Results}

\subsection{Screening, Analysis, and Cloning of CsC4H Candidate Genes}

After careful analysis of the $\mathrm{Cs} C 4 \mathrm{H}$ sequences based on the nine transcriptome databases and one genome database, three $\mathrm{CsC} 4 \mathrm{H}$ transcripts were screened out after removing redundancies. The accession numbers of the three CsC4H genes in GenBank are KY615675 (CsC4Ha), KY615676 $(\mathrm{Cs} C 4 \mathrm{Hb})$, and $\mathrm{KY} 61567$ ( $\mathrm{Cs} C 4 \mathrm{Hc})$. CsC4Ha, $\mathrm{CsC} 4 \mathrm{Hb}$, and $\mathrm{CsC}_{5} 4 \mathrm{Hc}$ were isolated using PCR, with cDNA from Camellia sinensis leaves as a template using specific primers (Table 1). Both $\mathrm{CsC} 4 \mathrm{Ha}$ and $\mathrm{CsC} 4 \mathrm{Hb}$ have a 1518-bp open reading frames that code for a 505-amino acid protein. They have a predicted molecular mass of $58.15 \mathrm{kDa}$ and $58.00 \mathrm{kDa}$ and a predicted isoelectric point (pI) of 9.29 and 9.26, respectively. $\mathrm{CsC} 4 \mathrm{Hc}$ has a 1635 -bp open reading frame that codes for a 544 -amino acid protein, with a predicted molecular mass of $62.95 \mathrm{kDa}$ and a pI of 8.68 (Figure S1).

\subsection{Bioinformatics Analysis}

DNAMAN software (Lynnon Corporation, San Ramon, CA, USA) analysis shows that the amino acid sequences of $C_{s} \mathrm{C} 4 \mathrm{Ha}$ share $93.07 \%$ identity with that of $\mathrm{Cs}_{s} \mathrm{C} 4 \mathrm{Hb}$. The amino acid sequences of $\mathrm{CsC} 4 \mathrm{Ha}$ and $\mathrm{CsC} 4 \mathrm{Hb}$ share only $59.93 \%$ and $58.82 \%$ identity with $\mathrm{CsC} 4 \mathrm{Hc}$, respectively.

To investigate the evolutionary relationship among $\mathrm{Cs} \mathrm{C} 4 \mathrm{Hs}$ and $\mathrm{C} 4 \mathrm{Hs}$ from other plant species, a phylogenetic tree was constructed using a neighbor-joining method. As shown in Figure 2, the phylogenetic tree was divided into five main groups: including Angiosperm Class I group (dicot and monocot), Angiosperm Class II group (dicot and monocot), Gymnosperm group, Bryophyte group, and Pteridophyte group. $\mathrm{Cs}_{s} \mathrm{C} 4 \mathrm{Ha}$ and $\mathrm{Cs}_{s} \mathrm{C} 4 \mathrm{Hb}$ belong to Angiosperm Class I and $\mathrm{Cs}_{s} \mathrm{C} 4 \mathrm{Hc}$ belongs to Angiosperm Class II. 


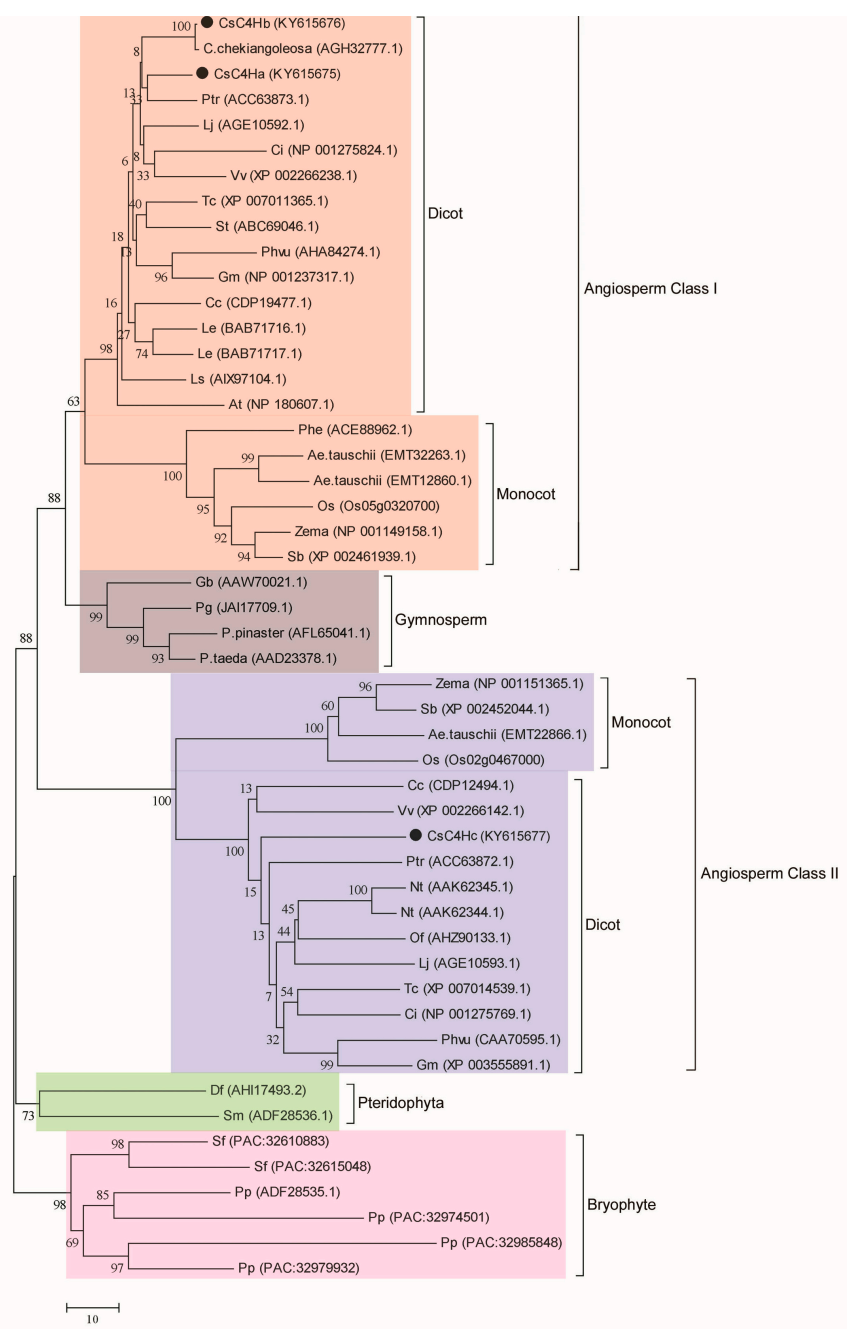

Figure 2. Phylogenetic tree of $\mathrm{Cs} C 4 \mathrm{Hs}$ and $\mathrm{C} 4 \mathrm{Hs}$ from other plants. The bars represent the evolutionary distance. $\mathrm{Cs} 44 \mathrm{Hs}$ are indicated by a circle $(\bullet)$. The following sequences were analyzed: Camellia sinensis C4Hb (KY615676), Camellia chekiangoleosa (AGH32777.1), C. sinensis C4Ha (KY615675), Populus trichocarpa (ACC63873.1), Citrus sinensis (NP_001275824.1), Vitis vinifera (XP_002266238.1), Lonicera japonica (AGE10592.1), Theobroma cacao (XP_007011365.1), Solanum tuberosum (ABC69046.1), Phaseolus vulgaris (AHA84274.1), Glycine max (NP_001237317.1), Coffea canephora (CDP19477.1), Lithospermum erythrorhizon (BAB71716.1), L. erythrorhizon (BAB71717.1), Lactuca sativa (AIX97104.1), Arabidopsis thaliana (NP_180607.1), Phyllostachys edulis (ACE88962.1), Aegilops tauschii (EMT32263.1), A. tauschii (EMT12860.1), Oryza sativa (Os05g0320700), Zea mays (NP_001149158.1), Sorghum bicolor (XP_002461939.1), Ginkgo biloba (AAW70021.1), Picea glauca (JAI17709.1), Pinus pinaster (AFL65041.1), Pinus taeda (AAD23378.1), Z. mays (NP_001151365.1), S. bicolor (XP_002452044.1), A. tauschii (EMT22866.1), O. sativa (Os02g0467000), C. canephora (CDP12494.1), V. vinifera (XP_002266142.1), C. sinensis C4Hc (KY615677), P. trichocarpa (ACC63872.1), Nicotiana tabacum (AAK62345.1), N. tabacum (AAK62344.1), Osmanthus fragrans (AHZ90133.1), Lonicera japonica (AGE10593.1), T. cacao (XP_007014539.1), C.s sinensis (NP_001275769.1), P. vulgaris (CAA70595.1), G. max (XP_003555891.1), D. fragrans (AHI17493.2), Selaginella moellendorffii (ADF28536.1), Sphagnum fallar (PAC:32610883), S. fallar (PAC:32615048), Physcomitrella patens (ADF28535.1), P. patens (PAC:32974501), P. patens (PAC:32985848), and P. patens (PAC:32979932).

Figure 3 shows the amino acid sequence alignment of three $C$. sinensis $\mathrm{C} 4 \mathrm{Hs}$ with known functional $\mathrm{C} 4 \mathrm{Hs}$ in other plants. There are five SRS (P450 substrate recognition sites) regions in these sequences, in addition to a heme-binding domain $\left(\mathrm{P}_{474} \mathrm{FGXGRRSCPG} \mathrm{F}_{484}\right)$ and a hinge region $\left(\mathrm{P}_{64} \mathrm{PGPXXXP} \mathrm{P}_{72}\right)$. 
The Angiosperm Class I proteins, including CsC4Ha and $\mathrm{CsC} 4 \mathrm{Hb}$, are conserved at the $\mathrm{N}$-terminal and have a 21-amino acid N-terminal hydrophobic domain which is flanked by an acidic residue (Asp) and several basic residues [23]. This region is predicted to be a signal-anchor sequence and to determine the correct orientation of P450s in the Endoplasmic Reticulum (ER) [24]. However, the Angiosperm Class II, including the $\mathrm{CsC} 4 \mathrm{Hc}$ sequence, is not conserved in this region, which may result in different subcellular localization and different physiological functions.

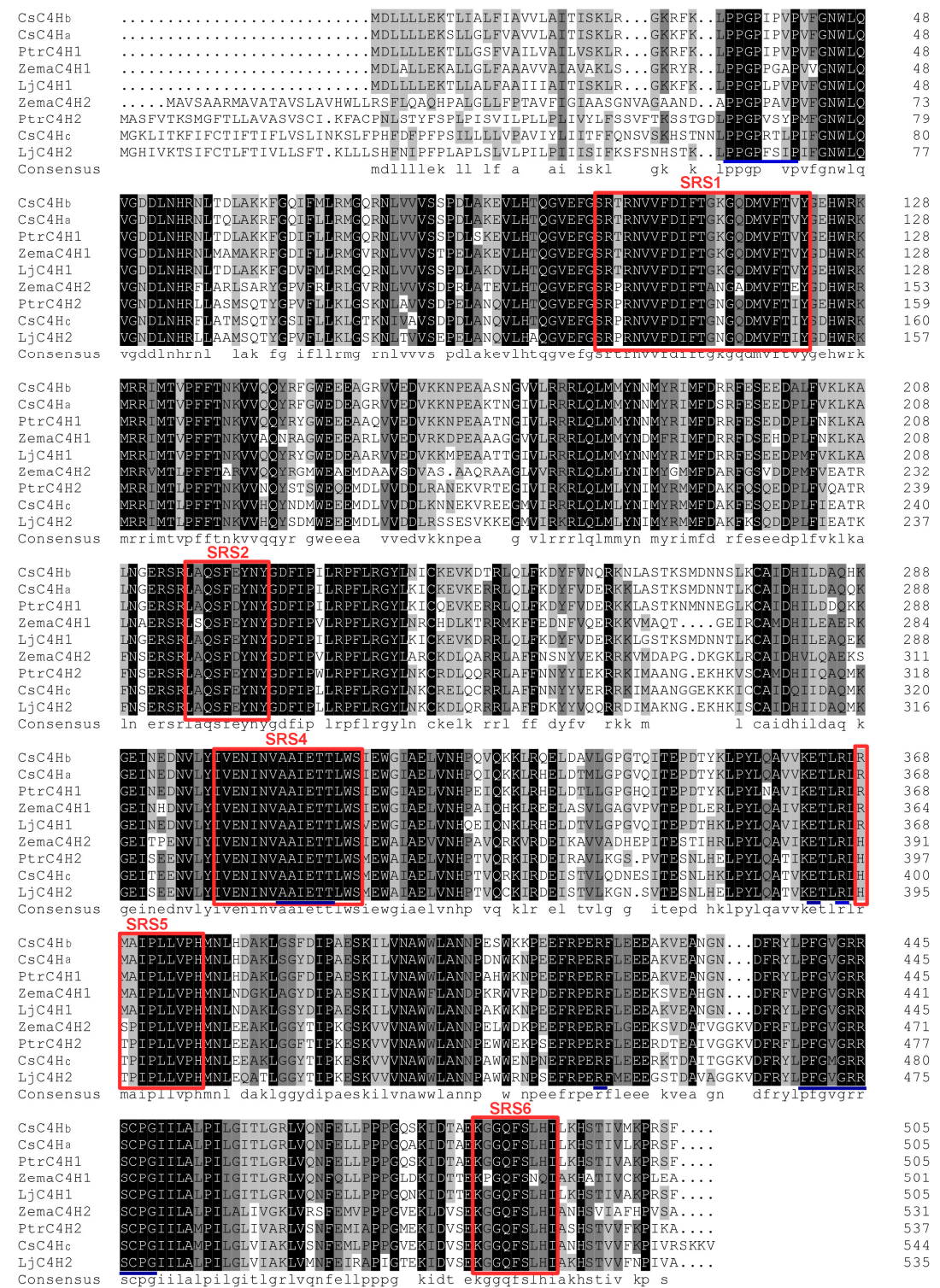

Figure 3. Multiple sequence alignment of $\mathrm{Cs} C 4 \mathrm{Hs}$ with $\mathrm{C} 4 \mathrm{Hs}$ from other plants. The following sequences are analyzed: C. sinensis $\mathrm{C} 4 \mathrm{Hb}(\mathrm{CsC} 4 \mathrm{Hb}, \mathrm{KY} 615676), \mathrm{C}$. sinensis $\mathrm{C} 4 \mathrm{Ha}$ (CsC4Ha, KY615675), P. trichocarpa C4H1 (PtrC4H1, ACC63873.1), Z. mays C4H1 (ZmC4H1, NP_001149158.1), L. japonica C4H1 (LjC4H1, AGE10592.1), Z. mays C4H2 (ZmC4H2, NP_001151365.1), P. trichocarpa C4H2 (PtrC4H2, ACC63872.1), C. sinensis C4Hc (CsC4Hc, KY615677), and L. japonica C4H2 (LjC4H2, AGE10593.1). Completely identical residues are reverse-displayed, while residues with dark gray, light gray, and white backgrounds are conserved, weakly similar, and non-similar residues, respectively. Underlined regions indicate P450-featured motifs, i.e., the hinge region, the T-containing binding pocket motif, the ERR triad and the Haem-domain, while boxes represent the five P450 substrate recognition sites (SRS) regions. 


\subsection{Heterologous Expression in Yeast and Enzymatic Analysis of CsC4H Proteins}

We expressed $C_{s} \mathrm{C} 4 \mathrm{Hs}$ recombinant proteins in a genetically modified S. cerevisiae strain, i.e., WAT11. PCR products of $\mathrm{CsC}_{\mathrm{S}} \mathrm{Ha}, \mathrm{Cs} 4 \mathrm{H} \mathrm{H}$, and $\mathrm{CsC}_{\mathrm{S}} \mathrm{H} \mathrm{Hc}$ were ligated into the destination vector pYES-DEST52 (Figure 4A). The resulting pYES-DEST52-CsC4Ha, pYES-DEST52-CsC4Hb, and pYES-DEST52-CsC4Hc were transformed into S. cerevisiae WAT11. The enzymatic catalytic identity of the three proteins was verified by enzyme assays using trans-cinnamic acid as a substrate, which was added to the yeast culture. The product $p$-coumarate was detected by HPLC analysis using an empty vector, and pYES-DEST52-CsC4Hs without a substrate as controls, respectively (Figure 4C). The peak area of the enzymatic product indicates that three recombinant $\mathrm{Cs} C 4 \mathrm{Hs}$ are able to convert $t$-cinnamate to yield $p$-coumarate when expressed in yeast.

A.

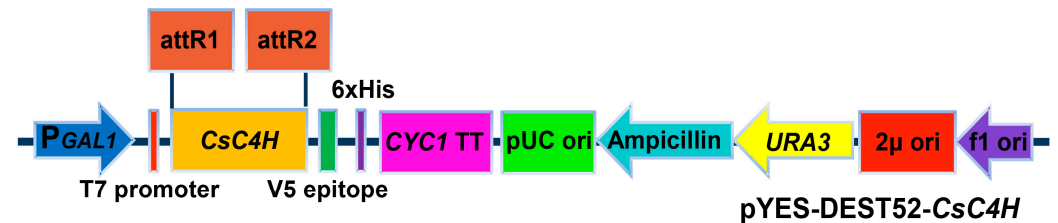

B.
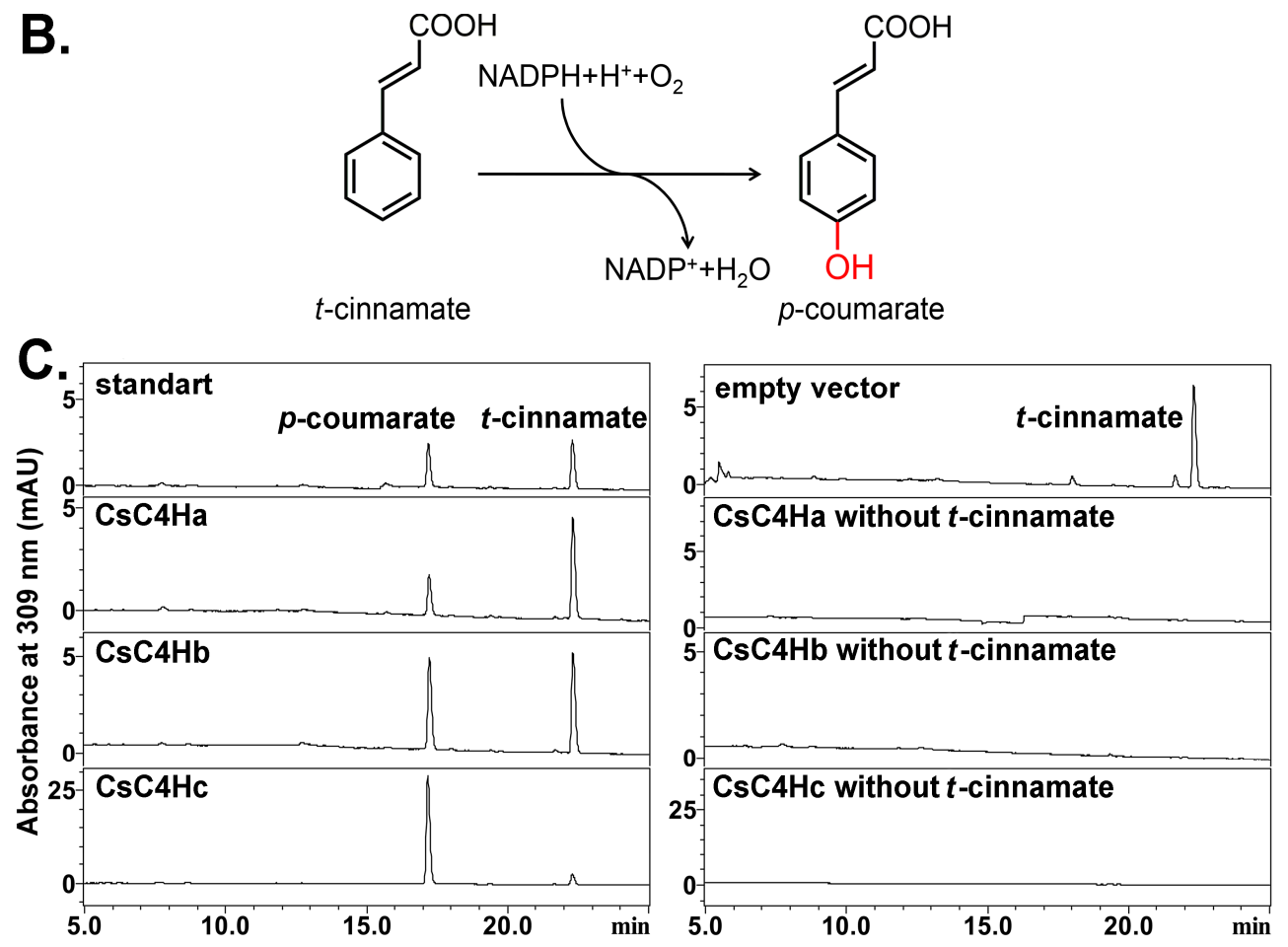

Figure 4. Heterologous expression in yeast and enzymatic activity analysis of $\mathrm{CsC} 4 \mathrm{H}$ proteins. (A) The expression vector of pYES-DEST52-CsC4Hs; and (B) The hydroxylation of $t$-cinnamate to $p$-coumarate was catalyzed by $\mathrm{Cs} C 4 \mathrm{H}$. (C) The left panel shows the HPLC results of standard $t$-cinnamate and $p$-coumarate and the reaction products of WAT11 (pYES-DEST52-CsC4Hs) using $t$-cinnamate as the substrate; the right panel shows the HPLC results of the control empty vector and WAT11 (pYES-DEST52-CsC4Hs) without $t$-cinnamate as the substrate. Detection was performed at $309 \mathrm{~nm}$.

\subsection{Real-Time PCR Analysis of C4H Genes Expression in C. sinensis}

To analyze the expression patterns of the $\mathrm{Cs} C 4 \mathrm{H}$ genes in various tissues and at different developmental stages, quantitative real-time PCR was performed using gene-specific primers. The expression patterns of the three $\mathrm{Cs} C 4 \mathrm{H}$ genes are found to be distinct from each other (Figure 5) 
$\mathrm{CsC} 4 \mathrm{Ha}$ is highly expressed in the 4 th leaf and the roots. The expression level of $\mathrm{CsC} 4 \mathrm{Hb}$ in tender leaves is significantly higher than that in old leaves, stems, and roots, which is consistent with the flavonoid accumulation pattern in tea plants [19]. Among the various tissues, $C s C 4 H c$ is mainly expressed in the young stems. In leaves at different developmental stages, $\mathrm{Cs} C 4 \mathrm{Hc}$ is relatively highly expressed in old leaves compared with tender leaves.



Figure 5. Expression pattern of $\mathrm{CsC} 4 \mathrm{H}$ genes in various tissues based on quantitative real-time analysis. The normalized transcripts in the buds were set arbitrarily to one. The data represent the mean standard deviation from three independent measurements.

Phenylpropanoid compounds can be induced by various biotic or abiotic stresses, such as high UV light intensity, wounding, and pathogen attack [25]. Therefore, we analyzed the inducible expression patterns of $\mathrm{CsC}_{\mathrm{S}} \mathrm{H}$ genes in response to different abiotic stresses, including UVB, heat stress, ABA, sucrose, dark conditions, SA, red light, and blue light (Figure 6). The results show that the levels of the three genes are increased approximately 2-6-fold in the sucrose and SA treatments compared to the control. ABA and blue light significantly increase the expressions of $\mathrm{CsC}_{\mathrm{S}} \mathrm{H} \mathrm{H}$ and $\mathrm{CsC} 4 \mathrm{Hb}$. By contrast, darkness treatment decreases the expressions of $\mathrm{CsC}_{s} \mathrm{Ha}$ and $\mathrm{CsC} 4 \mathrm{Hb}$. In addition, $\mathrm{CsC} 4 \mathrm{Hb}$ is up-regulated under heat stress.

The CsGAPDH gene was used as an internal control. Induced expression analysis of CsC4Hs in tea leaves subjected to $100 \mathrm{mM} \mathrm{ABA}, 90 \mathrm{mM}$ sucrose or dark treatment for $12 \mathrm{~h}$. Induced expression analysis of $\mathrm{CsC} 4 \mathrm{Hs}$ in tea leaves under $20 \mathrm{mM} \mathrm{SA}$ and in tea leaves treated with red $(655-660 \mathrm{~nm})$ or blue light (655-660 nm) for $48 \mathrm{~h}$. Induced expression analysis of CsC4Hs in tea leaves exposed to UVB or heat stress for $30 \mathrm{~min}$ was conducted. The data represent the mean standart deviation (SD) from three independent measurements. 


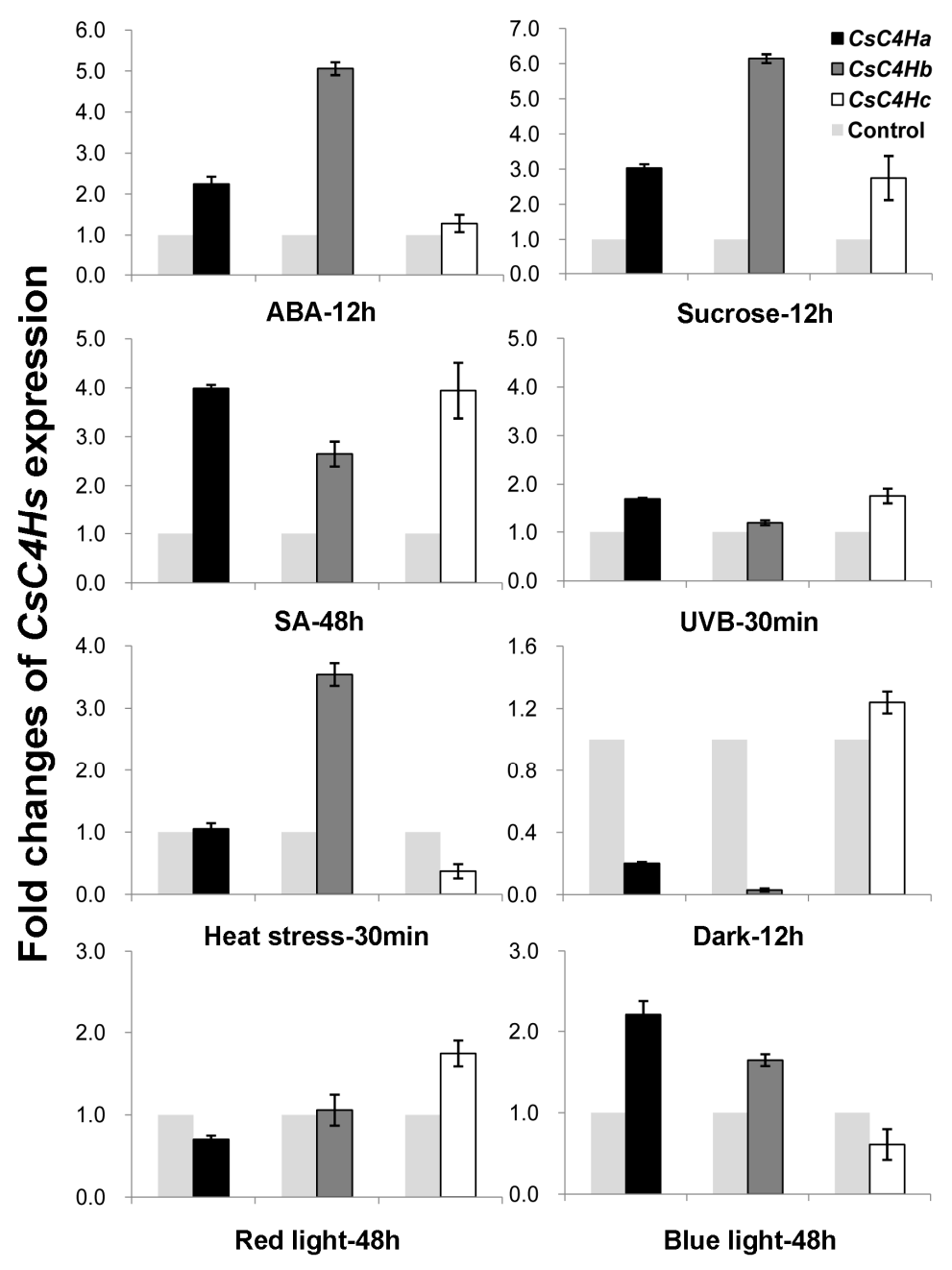

Figure 6. The transcript levels of $\mathrm{CsC}_{\mathrm{C}} \mathrm{H}$ s under different abiotic stresses. ABA: abscisic acid; SA: salicylic acid; UVB: ultraviolet radiation $b$.

\section{Discussion}

Tea leaves of $C$. sinensis are an important non-alcoholic beverage resource [26]. The tea beverage is becoming increasingly popular worldwide because of its refreshing, mild stimulatory and medicinal properties [27]. Thus, research on the genes encoding crucial metabolic enzymes that are responsible for the biosynthesis of chemicals is essential and critical in understanding plant metabolic pathways. $\mathrm{C} 4 \mathrm{H}$ is a key gene in the phenylpropanoid pathway; their function determines the downstream synthesis of flavonoid compounds and lignin.

$\mathrm{C} 4 \mathrm{H}$ genes are known to exist as small gene families in various plants. For example, four homologous genes of $\mathrm{C} 4 \mathrm{H}$ have been detected in Populus tremuloides and P. kitakamiensis [28]. In addition, two $\mathrm{C} 4 \mathrm{H}$ genes have been detected in Leucaena leucocephala [5], and there are at least two $\mathrm{C} 4 \mathrm{H}$ genes in C. acuminata and Brassica napus $[17,18]$. However, $\mathrm{C} 4 \mathrm{H}$ is encoded by a single-copy gene in many species, such as Arabidopsis, parsley, P. henryana, and S. baicalensis $[13,15,16,29]$. To confirm the numbers of $\mathrm{CsC} 4 \mathrm{H}$ members, we carefully screened all available transcriptome and genome databases, and three $\mathrm{Cs} C 4 \mathrm{H}$ transcripts were screened out after redundancies were removed. Three $\mathrm{C} 4 \mathrm{H}$ transcripts were cloned fromC. sinensis, which indicates there are at least three $\mathrm{C} 4 \mathrm{H}$ genes in the tea genome. The addition of a substrate to a yeast culture experiment showed that the three recombinant $\mathrm{C} 4 \mathrm{H}$ proteins had enzymatic activities that resulted in the formation of 4-coumarate (or para-coumarate). Quantitative expression analysis indicated different expression patterns of the CsC4Hs in various 
tissues and under abiotic stresses. The tissue- and induction-specific expressions of CsC4Hs indicated their different functions in vivo.

According to the phylogenetic tree, the angiosperms were classified into two groups (Class I and Class II dicot and monocot). $\mathrm{Cs}_{\mathrm{C}} 4 \mathrm{Ha}$ and $\mathrm{Cs}_{\mathrm{C}} \mathrm{CHb}$ belong to Class I dicot and monocot, whereas $\mathrm{Cs}$ C4Hc belongs to Class II dicot and monocot. This branch of the phylogenetic tree indicates that gene duplication prior to the divergence of monocots and dicots led to the divergent isoforms in angiosperms [23]. However, some dicots have lost their Class II protein, and the complete sequence of the Arabidopsis genome revealed no Class II gene [15].

Different functions of C4Hs in Class I and Class II have been reported. Eucalyptus Class II C4H is primarily involved in stress responses, as well as in wood lignin biosynthesis, and Class I C4H is constitutively expressed in any tissue that requires phenylpropanoid metabolites [30]. There are three $\mathrm{C} 4 \mathrm{H}$ gene models in the P. trichocarpa genome. Transcripts of $\mathrm{PtrC} 4 \mathrm{H} 1$ and $\mathrm{PtrC} 4 \mathrm{H} 2$ (belonging to Class I) are abundant in differentiating xylem, suggesting that both are important in monolignol biosynthesis. Transcripts of $P \operatorname{trC} 4 \mathrm{H} 3$ (belonging to Class II), not previously characterized, have been shown to have low or no expression in all examined tissues [31]. C4H genes from $P$. tremuloides and $P$. trichocarpa are differentially expressed in tissues, and individual isoforms have been shown to play specific physiological roles in development [32]. In this work, the expression patterns of $\mathrm{CsC}_{5} \mathrm{Hb}$ belonged to Class I in different tissues is consistent with the flavonoid accumulation pattern [19], indicating that $\mathrm{Cs} C 4 \mathrm{Hb}$ are involved in flavonoid biosynthesis in tea plants.

Phenylpropanoid compounds can be induced by various biotic and abiotic stresses [25]. $\mathrm{C} 4 \mathrm{H}$ is induced by light; UVB, such as in Arabidopsis, Dryopteris fragrans, and Salvia miltiorrhiza [33-35]; wounding [36]; $\mathrm{NaCl}$ [37]; cold; $\mathrm{H}_{2} \mathrm{O}_{2} ; \mathrm{ABA} ; \mathrm{SA}$, such as in Carthamus tinctorius and kenaf [38,39]; and pathogen attack, for example, in cucumber and melon plants, $\mathrm{C} 4 \mathrm{H}$ is up-regulated by viruses [40]; drought [41]; and elicitors [42]. Our work showed that the CsC4Ha in Class I and CsC4Hc in Class II were obviously induced by SA. This suggests that these two genes are involved in the defense of tea plants.

\section{Conclusions}

We cloned three $\mathrm{Cs}_{\mathrm{S}} 4 \mathrm{H}$ transcripts, and the enzymatic activity of these proteins was characterized in vitro. The amino acid sequence alignment of $\mathrm{Cs}_{5} \mathrm{C} H \mathrm{H}$ proteins and expression patterns of $\mathrm{CsC}_{5} \mathrm{H}$ genes in leaves at different developmental stages and abiotic stress treatments suggest they may have different subcellular localization and different physiological functions. The future work is under way.

Supplementary Materials: The following are available online at www.mdpi.com/2073-4425/8/8/193/s1. Figure S1: Gel electrophoresis of PCR to clone CsC4Hs.

Acknowledgments: This work was supported by the Natural Science Foundation of China (grant numbers: 31570694 and 31470689), the Specialized Research Fund for the Doctoral Program of Higher Education (grant numbers: 20133418130001), the Natural Science Foundation of Anhui Province, China (grant numbers: 1708085MC58), the Special Foundation for Independent Innovation of Anhui Province, China (grant numbers: 13Z03012), and the Biology Key Subject Construction of Anhui.

Author Contributions: Shengbo Yao conceived and designed the experiments; Jinxin Xia performed the experiments; Jinxin Xia and Shengbo Yao analyzed the data; Ming Li, Mengqing Zhu, and Keyi Huang contributed reagents/materials/analysis tools; and Jinxin Xia and Yajun Liu wrote the paper.

Conflicts of Interest: The authors declare no conflict of interest.

\section{References}

1. Li, C.F.; Zhu, Y.; Yu, Y.; Zhao, Q.Y.; Wang, S.J.; Wang, X.C.; Yao, M.Z.; Luo, D.; Li, X.; Chen, L. Global transcriptome and gene regulation network for secondary metabolite biosynthesis of tea plant (Camellia sinensis). BMC Genom. 2015, 16, 560. [CrossRef] [PubMed] 
2. Cui, L.; Yao, S.; Dai, X.; Yin, Q.; Liu, Y.; Jiang, X.; Wu, Y.; Qian, Y.; Pang, Y.; Gao, L. Identification of UDP-glycosyltransferases involved in the biosynthesis of astringent taste compounds in tea (Camellia sinensis). J. Exp. Botany 2016, 67, 2285-2297. [CrossRef] [PubMed]

3. Tohge, T.; Fernie, A.R. An overview of compounds derived from the shikimate and phenylpropanoid pathways and their medicinal importance. Mini Rev. Med. Chem. 2017, 17, 1013-1027. [CrossRef]

4. Hahlbrock, K.; Scheel, D. Physiology and molecular biology of phenylpropanoid metabolism. Ann. Rev. Plant Biol. 2003, 40, 347-369. [CrossRef]

5. Kumar, S.; Omer, S.; Patel, K.; Khan, B.M. Cinnamate 4-hydroxylase (C4H) genes from Leucaena leucocephala: A pulp yielding leguminous tree. Mol. Biol. Rep. 2013, 40, 1265-1274. [CrossRef] [PubMed]

6. Ehlting, J.; Hamberger, B.; Million-Rousseau, R.; Werck-Reichhart, D. Cytochromes P450 in phenolic metabolism. Phytochem. Rev. 2006, 5, 239-270. [CrossRef]

7. Boerjan, W.; Ralph, J.; Baucher, M. Lignin biosynthesis. Ann. Rev. Plant Biol. 2003, 54, 519-546. [CrossRef] [PubMed]

8. Neutelings, G. Lignin variability in plant cell walls: Contribution of new models. Plant Scie. Int. J. Exp. Plant Biol. 2011, 181, 379. [CrossRef] [PubMed]

9. Havsteen, B.H. The biochemistry and medical significance of the flavonoids. Pharmacol. Ther. 2002, 96, 67-202. [CrossRef]

10. Kochs, G.; Grisebach, H. Phytoalexin synthesis in soybean: Purification and reconstitution of cytochrome P450 3,9-dihydroxypterocarpan 6A-hydroxylase and separation from cytochrome P450 cinnamate 4-hydroxylase. Arch. Biochem. Biophys. 1989, 273, 543-553. [CrossRef]

11. Kochs, G.; Werckreichhart, D.; Grisebach, H. Further characterization of cytochrome P450 involved in phytoalexin synthesis in soybean: Cytochrome P450 cinnamate 4-hydroxylase and 3,9-dihydroxypterocarpan 6A-hydroxylase. Arch. Biochem. Biophys. 1992, 293, 187-194. [CrossRef]

12. Achnine, L.; Blancaflor, E.B.; Rasmussen, S.; Dixon, R.A. Colocalization of L-phenylalanine ammonia-lyase and cinnamate 4-hydroxylase for metabolic channeling in phenylpropanoid biosynthesis. Plant Cell. 2004, 16, 3098-3109. [CrossRef] [PubMed]

13. Xu, H.; Park, N.I.; Li, X.; Kim, Y.K.; Lee, S.Y.; Park, S.U. Molecular cloning and characterization of phenylalanine ammonia-lyase, cinnamate 4-hydroxylase and genes involved in flavone biosynthesis in Scutellaria baicalensis. Bioresour. Technol. 2010, 101, 9715-9722. [CrossRef] [PubMed]

14. Mcnulty, J.; Nair, J.J.; Singh, M.; Crankshaw, D.J.; Holloway, A.C.; Bastida, J. Selective cytochrome P450 3A4 inhibitory activity of Amaryllidaceae alkaloids. Bioorg. Med. Chem. Lett. 2009, 19, 3233-3237. [CrossRef] [PubMed]

15. Raes, J.; Rohde, A.; Christensen, J.H.; Van de Peer, Y.; Boerjan, W. Genome-wide characterization of the lignification toolbox in Arabidopsis. Plant Physiol. 2003, 133, 1051-1071. [CrossRef] [PubMed]

16. Koopmann, E.; Logemann, E.; Hahlbrock, K. Regulation and Functional Expression of Cinnamate 4-Hydroxylase from Parsley. Plant Physiol. 1999, 119, 49-56. [CrossRef] [PubMed]

17. Li, W.; Yang, L.; Jiang, L.; Zhang, G.; Luo, Y. Molecular cloning and functional characterization of a cinnamate 4-hydroxylase-encoding gene from Camptotheca acuminata. Acta Physiol. Plant. 2016, 38, 1-9. [CrossRef]

18. Chen, A.H.; Chai, Y.R.; Li, J.N.; Chen, L. Molecular cloning of two genes encoding cinnamate 4-hydroxylase (C4H) from oilseed rape (Brassica napus). J. Biochem. Mol. Biol. 2007, 40, 247-260. [PubMed]

19. Jiang, X.; Liu, Y.; Li, W.; Zhao, L.; Meng, F.; Wang, Y.; Tan, H.; Yang, H.; Wei, C.; Wan, X.; et al. Tissue-Specific, Development-Dependent Phenolic Compounds Accumulation Profile and Gene Expression Pattern in Tea Plant (Camellia Sinensis). PLoS ONE 2013, 8, e62315. [CrossRef] [PubMed]

20. Lei, Z.; Gao, L.; Wang, H.; Chen, X.; Wang, Y.; Hua, Y.; Wei, C.; Wan, X.; Tao, X. The R2R3-MYB, bHLH, WD40, and related transcription factors in flavonoid biosynthesis. Funct. Integr. Genom. 2013, 13, 75-98.

21. Wheeler, D.L.; Barrett, T.; Benson, D.A.; Bryant, S.H.; Canese, K.; Chetvernin, V.; Church, D.M.; Dicuccio, M.; Edgar, R.; Federhen, S. Database resources of the National Center for Biotechnology Information. Nucleic Acids Res. 2002, 39, 13-16. [CrossRef]

22. Sato, Y.; Takaya, A.; Yamamoto, T. Meta-analytic approach to the accurate prediction of secreted virulence effectors in gram-negative bacteria. BMC Bioinf. 2011, 12, 1-12. [CrossRef] [PubMed]

23. Ro, D.K.; Mah, N.; Ellis, B.E.; Douglas, C.J. Functional characterization and subcellular localization of poplar (Populus trichocarpa $\times$ Populus deltoides) cinnamate 4-hydroxylase. Plant Physiol. 2001, 126, 317-329. [CrossRef] [PubMed] 
24. Sakaguchi, M.; Tomiyoshi, R.; Kuroiwa, T.; Mihara, K.; Omura, T. Functions of signal and signal-anchor sequences are determined by the balance between the hydrophobic segment and the N-terminal charge. Proc. Natl. Acad. Sci. USA 1992, 89, 16. [CrossRef] [PubMed]

25. Dixon, R.A.; Paiva, N.L. Stress-induced phenylpropanoid metabolism. Plant Cell 1995, 7, $1085-1097$. [CrossRef] [PubMed]

26. Cabrera, C.; Artacho, R.; Giménez, R. Beneficial Effects of Green Tea-A Review. J. Am. Coll. Nutr. 2006, 25, 79-99. [CrossRef] [PubMed]

27. Mukhtar, H.; Ahmad, N. Tea polyphenols: Prevention of cancer and optimizing health. Am. J. Clin. Nutr. 2000, 71, 1698S. [PubMed]

28. Arai, M.; Nao-I, N.; Sawada, A.; Hayashida, T. Isolation and analysis of cinnamic acid 4-hydroxylase homologous genes from a hybrid aspen, Populus kitakamiensis. Biosci. Biotechnol. Biochem. 1996, 60, 1586-1597.

29. Liu, S.; Hu, Y.; Wang, X.; Han, L.; Song, S.; Cheng, H.; Lin, Z. Isolation and characterization of a gene encoding cinnamate 4-hydroxylase from Parthenocissus henryana. Mol. Biol. Rep. 2009, 36, 1605-1610. [CrossRef] [PubMed]

30. Harakava, R. Genes encoding enzymes of the lignin biosynthesis pathway in Eucalyptus. Genet. Mol. Biol. 2005, 28, 601-607. [CrossRef]

31. Shi, R.; Sun, Y.H.; Li, Q.Z.; Heber, S.; Sederoff, R.; Chiang, V.L. Towards a systems approach for lignin biosynthesis in Populus trichocarpa: Transcript abundance and specificity of the monolignol biosynthetic genes. Plant Cell Physiol. 2010, 51, 144-163. [CrossRef] [PubMed]

32. Lu, S.; Zhou, Y.; Li, L.; Chiang, V.L. Distinct roles of cinnamate 4-hydroxylase genes in Populus. Plant Cell Physiol. 2006, 47, 905-914. [CrossRef] [PubMed]

33. Jin, H.; Cominelli, E.; Bailey, P.; Parr, A.; Mehrtens, F.; Jones, J.; Tonelli, C.; Weisshaar, B.; Martin, C. Transcriptional repression by AtMYB4 controls production of UV-protecting sunscreens in Arabidopsis. EMBO J. 2000, 19, 6150-6161. [CrossRef] [PubMed]

34. Li, Y.; Sun, L.; Wang, H.; Gao, R.; Zhang, J.; Hu, B.; Chang, Y. Cloning and expression analysis of phenylalanine ammonia-lyase (PAL) gene family and cinnamate 4-hydroxylase (C4H) from Dryopteris fragrans. Biologia 2015, 70, 606-614. [CrossRef]

35. Huang, B.; Duan, Y.; Yi, B.; Sun, L.; Lu, B.; Yu, X.; Sun, H.; Zhang, H.; Chen, W. Characterization and expression profiling of cinnamate 4-hydroxylase gene from Salvia miltiorrhiza in rosmarinic acid biosynthesis pathway. Russ. J. Plant Physiol. 2008, 55, 390-399. [CrossRef]

36. Kim, J.H.; Yun, P.Y.; Lee, Y.K.; Lim, Y.P.; Lee, M.C. cDNA cloning and sequence analysis of the rice Cinnamate-4-Hydroxylase gene, a cytochrome P450-dependent monooxygenase involved in the general phenylpropanoid pathway. J. Plant Biol. 2005, 48, 311-318.

37. Sadeghi, M.; Dehghan, S.; Fischer, R.; Wenzel, U.; Vilcinskas, A.; Kavousi, H.R.; Rahnamaeian, M. Isolation and characterization of isochorismate synthase and cinnamate 4-hydroxylase during salinity stress, wounding, and salicylic acid treatment in Carthamus tinctorius. Plant Signal. Behav. 2013, 8, 2420-2423. [CrossRef] [PubMed]

38. Betz, C.; Mccollum, T.G.; Mayer, R.T. Differential expression of two cinnamate 4-hydroxylase genes in 'Valencia' orange (Citrus sinensis Osbeck). Plant Mol. Biol. 2001, 46, 741-748. [CrossRef] [PubMed]

39. Jonggeun, K.; Bosung, C.; Natarajan, S.; Hanhong, B. Expression analysis of kenaf cinnamate 4-hydroxylase $(\mathrm{C} 4 \mathrm{H})$ ortholog during developmental and stress responses. Plant Omics 2013, 6, 65-72.

40. Bellés, J.M.; Lopéz-Gresa, M.P.; Fayos, J.; Pallás, V.; Rodrigo, I.; Conejero, V. Induction of cinnamate 4-hydroxylase and phenylpropanoids in virus-infected cucumber and melon plants. Plant Sci. 2008, 174, 524-533. [CrossRef]

41. Phimchan, P.; Chanthai, S.; Bosland, P.W.; Techawongstien, S. Enzymatic changes in phenylalanine ammonia-lyase, cinnamic-4-hydroxylase, capsaicin synthase, and peroxidase activities in Capsicum under drought stress. J. Agric. Food Chem. 2014, 62, 7057. [CrossRef] [PubMed]

42. Pei, X.; Guo, H.; Wan, F.; Cheng, H. Phenylalanine ammonia-lyase and cinnamate 4-hydroxylase genes' response to HHO in Eupatorium adenophorum. Weed Biol. Manag. 2012, 12, 177-182. [CrossRef]

(C) 2017 by the authors. Licensee MDPI, Basel, Switzerland. This article is an open access article distributed under the terms and conditions of the Creative Commons Attribution (CC BY) license (http:/ / creativecommons.org/licenses/by/4.0/). 